\title{
CUATRO EPÍGRAFES CONSERVADOS EN LA FUNDACIÓN CASA DE MEDINA SIDONIA. SIGLOS XV-XVIII
}

\section{FOUR INSCRIPTIONS PRESERVED IN THE FOUNDATION HOUSE OF MEDINA SIDONIA. XV-XVIII CENTURIES}

\author{
Domingo BELTRÁN CORBALÁN \\ Pedro MARTÍNEZ CAVERO \\ Universidad de Murcia
}

Resumen: Este trabajo estudia cuatro epígrafes conservados en el palacio de los duques de Medina Sidonia en Sanlúcar de Barrameda (Cádiz). El primero es una inscripción fragmentada escrita en letra gótica; el segundo recoge la leyenda de las siete doncellas de Simancas; el tercero es una serie de anotaciones en grafito. Estos tres proceden de la planta baja del palacio. El cuarto epígrafe corresponde a la inscripción de la fuente de la iglesia-convento de la Merced de Sanlúcar, mandada realizar por Manuel Alonso Pérez de Guzmán, octavo duque de Medina Sidonia.

Palabras clave: Fundación Casa de Medina Sidonia; epigrafia; siete doncellas, convento de la Merced, Manuel Alonso Pérez de Guzmán, Sanlúcar de Barrameda, Simancas.

Abstract: This paper examines four inscriptions preserved in the palace of the Dukes of Medina Sidonia in Sanlúcar de Barrameda (Cadiz). The first is a fragmented inscription in Gothic script; the second contains the legend of the seven maidens of Simancas; the third is a series of entries in graphite. These three are preserved on the palace ground floor. The fourth inscription is found on the fountain of La Merced, a churchconvent in Sanlúcar which was built by Manuel Alonso Pérez de Guzmán, the eighth duke of Medina Sidonia.

Keywords: Foundation House of Medina Sidonia, epigraphy, seven maidens, convent of La Merced, Manuel Alonso Pérez de Guzmán, Sanlúcar de Barrameda, Simancas.

\section{INTRODUCCIÓN}

La Fundación Casa de Medina Sidonia (FCMS) es una institución cultural, creada en 1990, que tiene entre sus fines la conservación y difusión del patrimonio histórico-artístico y documental. Respondiendo a esta finalidad, la Fundación conserva en su sede del palacio de los Guzmanes de Sanlúcar de Barrameda cuatro 


\section{Domingo Beltrán Corbalán y Pedro Martínez CAVERo \\ Cuatro epígrafes conservados en la Fundación CASA Medina Sidonia. Siglos XV-XVIII}

testimonios epigráficos fechados entre los siglos XV y XVIII. Este trabajo tiene como objetivo estudiarlos y contextualizarlos, ofrecer una lectura de su contenido y un análisis de sus caracteres internos y externos ${ }^{1}$.

En nuestro estudio seguimos un criterio cronológico y denominamos las inscripciones por el lugar en que se ubican o fueron halladas. Los tres primeros epígrafes pertenecen al mismo entorno del palacio, las galerías y salas de la planta baja. La cuarta es aliena, procede del convento de la Merced de Sanlúcar, históricamente vinculado al patronato de los duques de Medina Sidonia. Los epígrafes son:

1. Epígrafe de la moldura de la sala del arco almohade.

2-3. Epígrafes del muro Norte del corredor de la planta baja.

4. Epígrafe de la fuente de la Iglesia de la Merced.

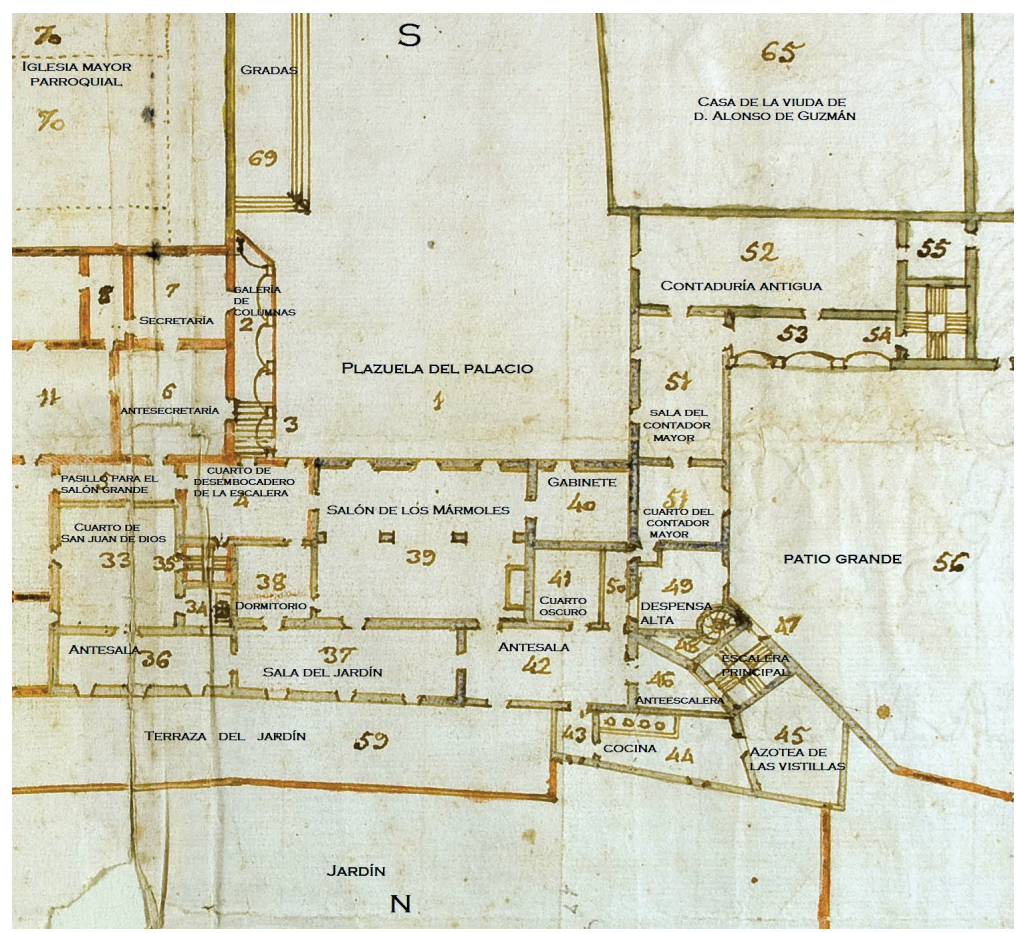

Fig. 1. Detalle del plano de la planta baja y primera del Palacio de Sanlúcar realizado por Juan Pedro Velázquez Gaztelu en 1762 (AGFCMS, leg. 235, doc. 10). El epígrafe 1 apareció en la sala situada bajo el Salón de los Mármoles (n. 39). Los epigrafes 2 y 3 se hallan en el corredor situado bajo la antesala del jardín (n. 42).

${ }^{1}$ V. GARCÍA LOBO, E. MARTÍN LÓPEZ: De Epigrafia medieval. Introducción y álbum, León, 1995. E. MARTÍN LOPEZ, V. GARCÍA LOBO: "La epigrafía medieval en España. Por una tipología de las inscripciones", III Jornadas Científicas sobre Documentación en la Hispania altomedieval (siglos VI-X), Universidad Complutense, Madrid, 2009, pp. 185-213. J. DE SANTIAGO FERNÁNDEZ, "La epigrafía: Evolución conceptual y metodológica”, Documenta \& Instrumenta, 1 (2004), pp. 203-220. N. RODRÍGUEZ SUAREZ: "Un repaso a través de los conceptos de epigrafía e inscripción”, Documenta \& Instrumenta, 10 (2012), pp. 147-154. 


\section{EPÍGRAFE DE LA MOLDURA DE LA SALA DEL ARCO ALMOHADE}

El palacio de los Guzmanes de Sanlúcar de Barrameda es un conjunto arquitectónico cuyos elementos más antiguos, levantados en parte sobre un ribat musulmán, datan del siglo XII. Tras la concesión del señorío en 1297 por Fernando IV, se estableció en este recinto Alonso Pérez de Guzmán el Bueno, primer señor de Sanlúcar.

El palacio ha sufrido diversas modificaciones y remodelaciones. A finales del siglo XV, Enrique Pérez de Guzmán, segundo duque de Medina Sidonia (1469-1492), derribó el "castillo viejo", y remodeló y amplió el edificio. El cronista Pedro Barrantes señala: "derribó hasta los fundamentos del alcaçar de la villa de Sanlucar de Barrameda, que estaba junto á la plaça é iglesia mayor, que no dexó mas de una torre por memoria". ${ }^{2}$ En estos años de finales del siglo XV y en los inmediatamente posteriores se debieron conformar una parte de las dependencias que están situadas en torno a la llamada plazuela del palacio que, en el siglo XVIII, describe el historiador y tesorero de la Casa ducal Juan Pedro Velázquez Gaztelu (Fig. 1). ${ }^{3}$

La última remodelación del palacio fue efectuada en el año 2005. En ella una parte del edificio fue adaptado a servicios de hostelería, que mantiene en la actualidad. Con anterioridad, en 1989, también se realizaron diversas actuaciones (Fig. 2. Remodelación de 1989). En el transcurso de estas obras de acondicionamiento, junto al arco almohade, aparecieron quince fragmentos de una inscripción medieval, que son los que trascribimos en este trabajo. Los fragmentos se encontraron al pie del arco, de donde fueron extraídos y conservados, quedando el resto del subsuelo sin alterar. ${ }^{4}$

\footnotetext{
${ }^{2}$ P. BARRANTES MALDONADO: Ilustraciones de la Casa de Niebla, ed. Federico Devis Márquez, Universidad de Cádiz, 1998, p. 405.

${ }^{3}$ M. P. PÉREZ GÓMEZ: "Planimetría del siglo XVIII del palacio de los Medina Sidonia en Sanlúcar de Barrameda", Laboratorio de Arte 23 (2011), pp. 333-349. Juan Pedro Velázquez Gaztelu (1710-1791) es marino e historiador ilustrado, tesorero de la Casa ducal y autor de una historia de Sanlúcar. M. ROMERO TALLAFIGO: "Historiografía manuscrita de Juan Pedro Velázquez Gaztelu (1770-1782). Su importancia para el Condado de Niebla”, Huelva y América: actas de las XI Jornadas de Andalucía y América, Huelva, 1993, pp.195-261.

${ }^{4}$ No hemos hallado referencias antiguas para esta sala baja del palacio, donde hoy se ubica la cafetería de la Fundación. La sala está situada, en parte, debajo del Salón de columnas o Salón de los mármoles, como aparece denominado en el plano del palacio realizado por Velázquez Gaztelu en 1762. Una excavación arqueológica en este lugar daría una información considerable para poder datar con mayor exactitud los distintos elementos arquitectónicos. También consideramos que
} 


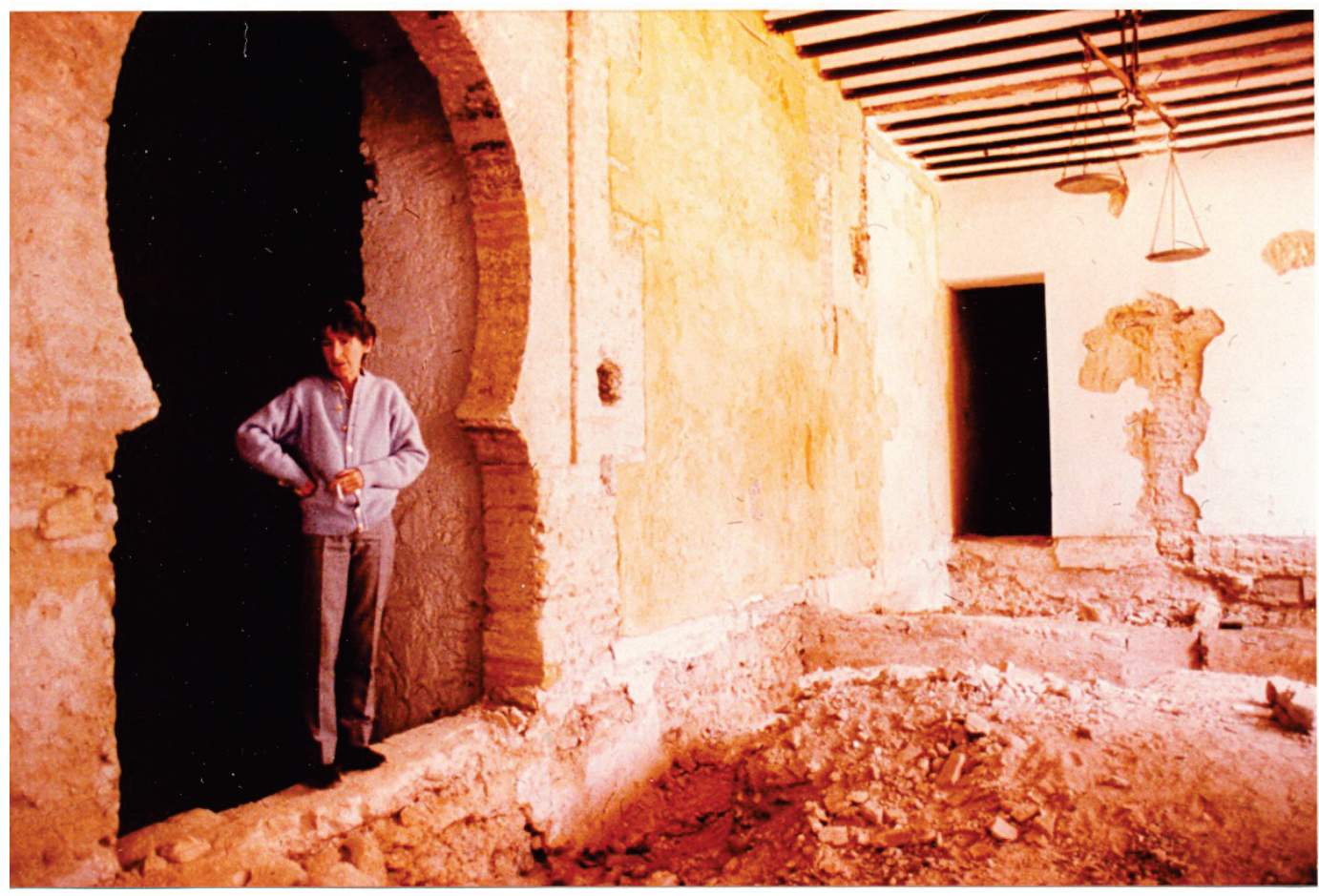

Fig. 2. Remodelación de 1989. El arco almohade divide la sala baja y el corredor Norte del palacio. En esta sala apareció el Epígrafe 1. En la fotografía, Luisa Isabel Álvarez de Toledo, vigesimoprimera duquesa de Medina Sidonia. Fotografia cedida por la FCMS.

Las quince piezas forman parte de una moldura de yeso que iría empotrada en la pared, probablemente sobre el arco. Los fragmentos conservados tienen las dimensiones siguientes: entre 13 y $32 \mathrm{~cm}$ de largo por $9 \mathrm{~cm}$ de ancho y una profundidad media de $8 \mathrm{~cm}$. La suma de todos los fragmentos es de $272 \mathrm{~cm}$ de longitud. En cuanto al grosor, se aprecia una diferencia de color en la parte superficial, de $2 \mathrm{~cm}$, que presenta un tono más claro. La moldura forma un friso cóncavo en el que aparece el texto. Éste fue pintado de color negro en contraste con el blanco de la superficie. Pensamos que formaba una sola línea de escritura. La altura de las letras oscila entre 6,30 y $8 \mathrm{~cm}$, y están contenidas en un campo epigráfico de $9 \mathrm{~cm}$ de alto.

Dado el estado fragmentario en el que se encuentra el epígrafe no hemos podido desarrollar su contenido. Por los caracteres gráficos y otros elementos externos, creemos que se puede fechar a finales del siglo XV o principios del siglo XVI. El tipo de escritura es una gótica minúscula caligráfica, aunque algunas le-

bajo el enlosado actual se puedan encontrar nuevos fragmentos de la inscripción y material arqueológico de diversa naturaleza. 
tras aparecen en módulo mayúsculo (por ejemplo, la A). Por ello, cabría adoptar una cronología tardía.

El texto conservado y la longitud de los quince fragmentos es la siguiente:

Frag. $1(32,5 \mathrm{~cm}):$ manter $^{5}$

Frag. 2 (25 cm): [...]ndo [...]

Frag. $3(25 \mathrm{~cm}):[\ldots]: t[u]$

Frag. $4(22 \mathrm{~cm}):[\ldots]$ loa $[\ldots]^{6}$

Frag. $5(21,5 \mathrm{~cm}):[]:. u[l]$

Frag. $6(21 \mathrm{~cm}):[\ldots]:[l \ldots]$

Frag. $7(21 \mathrm{~cm}):$ : $n o[\mathrm{n}]$

Frag. $8(17 \mathrm{~cm})$ : an

Frag. $9(17 \mathrm{~cm}):$ [a id]

Frag. $10(16 \mathrm{~cm}):[\ldots]$ alor

Frag. $11(15 \mathrm{~cm}):[\ldots] \mathrm{m}[\ldots]$

Frag. $12(14,5 \mathrm{~cm}):[\ldots]$ or

Frag. $13(14 \mathrm{~cm}):[\ldots] r t$

Frag. $14(13,5 \mathrm{~cm}):[o] a$

Frag. $15(13 \mathrm{~cm}):[\ldots]$
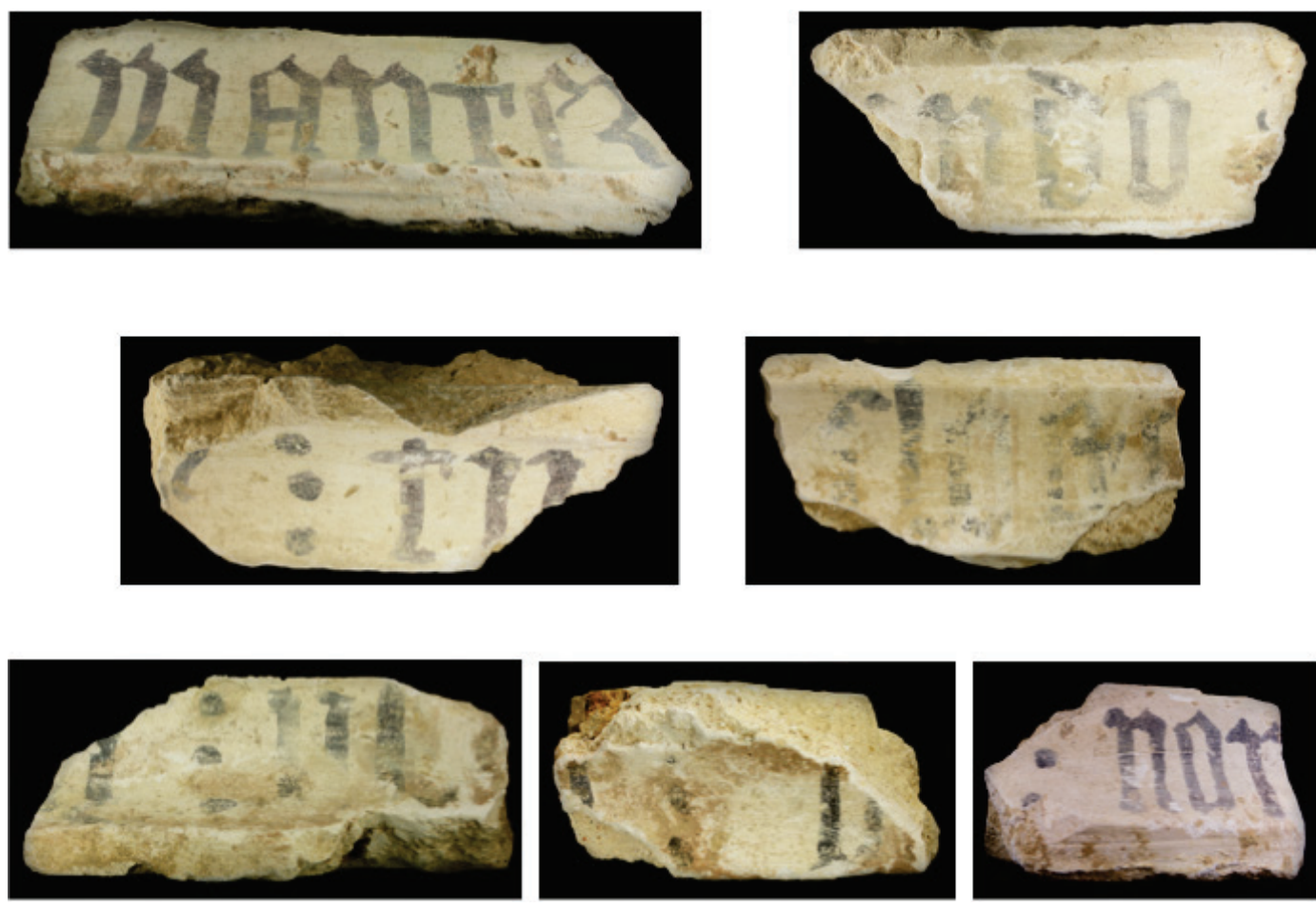

${ }^{5}$ Otra lectura posible es: mantr.

${ }^{6}$ Otra lectura posible es: [...]loa [...]. 

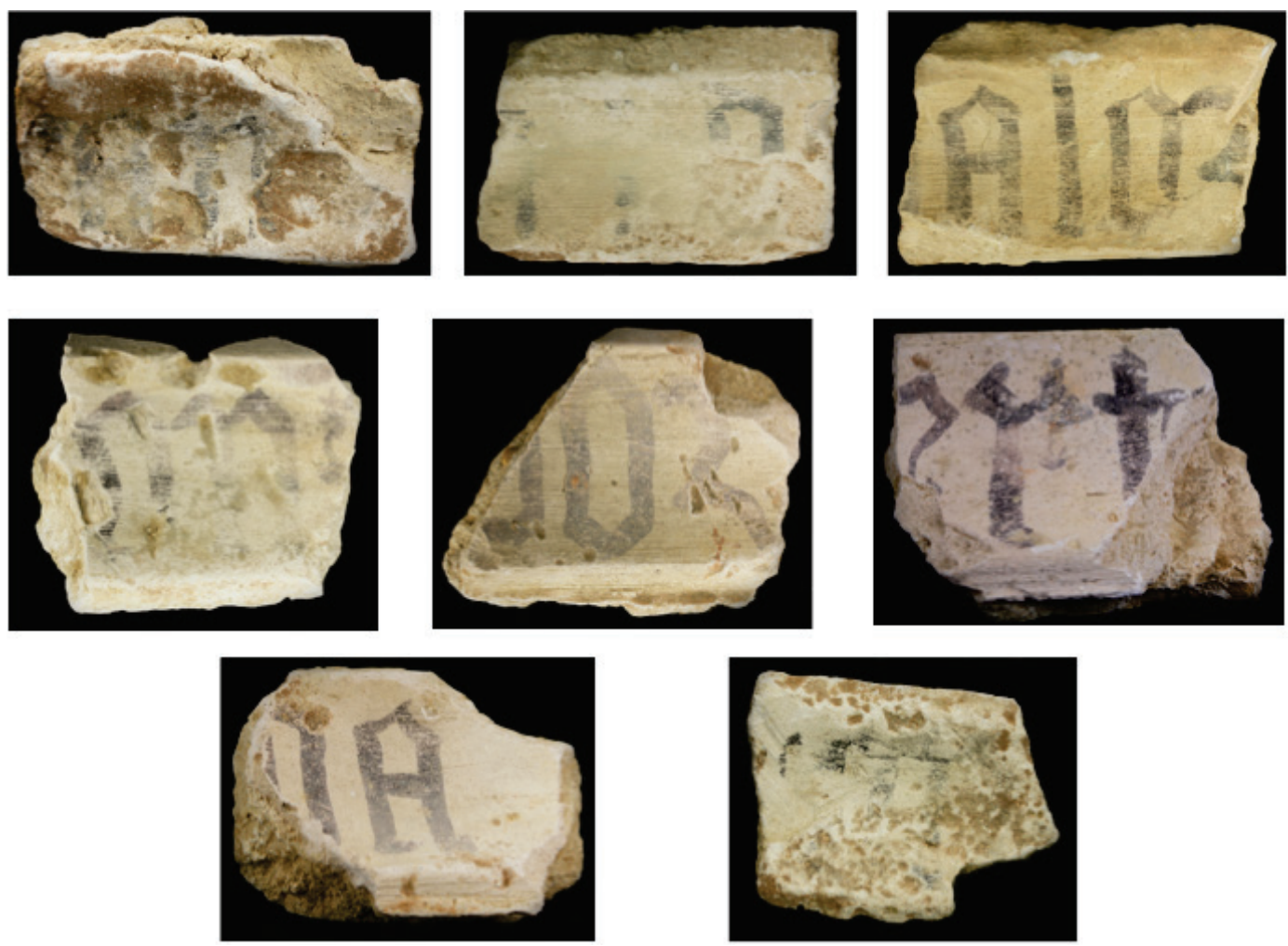

Fig. 3. Epígrafe de la moldura de la sala del arco almohade del palacio ducal de Medina Sidonia (Frag. 1-15). Fotografias IAPH.

\section{EPÍGRAFES DEL MURO NORTE DEL CORREDOR DE LA}

\section{PLANTA BAJA}

En el primer tramo del muro Norte del corredor interior de la planta baja del palacio ducal, entre las arcadas que se abren a la galería del jardín, se hallan ubicados los dos epígrafes que estudiamos a continuación. Sus características son diferentes, pero ambos aparecieron en 2005, como resultado de los trabajos de acondicionamiento del palacio, realizados en el marco de restauración general de los jardines y estancias interiores del edificio. Entonces se tomaron las medidas que han permitido su conservación. Para su protección se colocó un marco de madera y un cristal. Los epígrafes responden a una superficie de mayores dimensiones; ambos se hallan situados en una posición alta del muro (a 2,28 $\mathrm{m}$ el primero, y a 2,48 m el segundo sobre el suelo actual), por lo que para su realización debió de disponerse de algún tipo de andamiaje. 
3.1. Grafito 1 del muro Norte del corredor (epígrafe de las siete doncellas mancas)

Escritura sobre yeso en color negro y restos de policromía en el monograma y en algunas zonas del campo escriptorio. Regular estado de conservación; el texto aparece fragmentado como consecuencia del deterioro producido en el momento del hallazgo. Las dimensiones del campo epigráfico contenido dentro del marco de madera son de 73 por $90 \mathrm{~cm}$. El texto consta de seis líneas, más un monograma final, colocado en posición central. La caja de escritura de las cinco líneas iniciales es de 40 por $52 \mathrm{~cm}$. Las dimensiones del monograma (AS) son de 30 por 28 $\mathrm{cm}$. El interlineado es de $6 \mathrm{~cm}$ y el módulo de las letras de $5 \mathrm{~cm}$. Además del texto principal quedan restos de escrituras secundarias realizadas con posterioridad. El tipo de escritura es humanística corriente.

El texto del grafito es el siguiente:

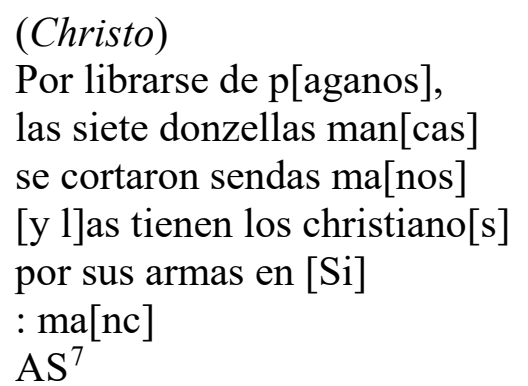

La inscripción reproduce una coplilla recogida en un romance popular que rememora la leyenda astur-leonesa del tributo de las cien doncellas y su variante de las siete doncellas de Simancas. ${ }^{8}$ La leyenda medieval ha sufrido diversas versiones, siendo recogida finalmente en un manuscrito del siglo XVIII titulado Anti-

\footnotetext{
${ }^{7}$ El estado incompleto de las terminaciones de los versos del epígrafe no permite una lectura segura de las letras finales y del monograma. Este podría leerse individualmente AS o SA. Interpretamos que completa la palabra Simancas. En la línea 5 podemos encontrar un trazo que puede corresponder con el inicio de la letra $\mathrm{S}$. La palabra aparecería cortada: $\mathrm{Si} / \mathrm{manc} / \mathrm{AS}$.

${ }^{8}$ Se trata de una leyenda etimológica que explica popularmente el nombre de Simancas, en realidad de origen romano. H. VELASCO MAÍLLO: "Leyendas y vinculaciones", La leyenda: antropología, historia, literatura: actas del coloquio celebrado en la Casa de Velázquez, Madrid 1989, p. 119. La leyenda de las siete doncellas de Simancas conmemora la erradicación del tributo pagado por la villa a los musulmanes. Para evitar su entrega, las siete muchachas de Simancas decidieron mutilarse una mano. Este acto de valentía desencadenó una repuesta militar cristiana que condujo a la victoria con la ayuda del apóstol Santiago. La villa de Simancas refleja esta leyenda en su escudo y la conmemora anualmente. La gesta tiene claros antecedentes en el mito de Teseo y retoma los elementos típicos del género: la doncella, el héroe que triunfa en combate, la ayuda de la divinidad y la cancelación del tributo. J. A. QUIJERA PEREZ: "El tributo de las cien doncellas. Un viejo mito mediterráneo", Revista de Folklore, 148 (1993), pp. 128-135.
} 
güedades de Simancas, del beneficiado de preste Manuel Bachiller. Este texto se basa en un manuscrito de 1580, desaparecido, cuya autoría se atribuye al licenciado Antonio Cabezudo, beneficiado de preste de la iglesia de El Salvador de Simancas 9 .

Esta última tradición nos sirve para situar nuestra hipótesis. Aunque no tenemos datos seguros para fijar la fecha de este epígrafe, entendemos que el testimonio de Sanlúcar recoge una tradición contemporánea a la del licenciado Cabezudo. El texto se puede situar estilísticamente en el siglo XVII, por lo que, en consecuencia, podríamos estar ante el testimonio epigráfico más antiguo conservado de esta tradición.

Cuestión diferente es determinar el motivo de la ubicación de este epígrafe en las galerías bajas del palacio ducal de Sanlúcar de Barrameda. Cabe pensar en la relación del duque de Medina Sidonia, Manuel Alonso Pérez de Guzmán y Silva (1579-1636) con la corte de Valladolid. Asimismo, sabemos que Manuel Alonso se retiró a sus señoríos andaluces donde desarrolló su afición a la literatura. ${ }^{10}$ En esta relación entre Valladolid y Sanlúcar puede encontrarse el origen de la inscripción que estudiamos.

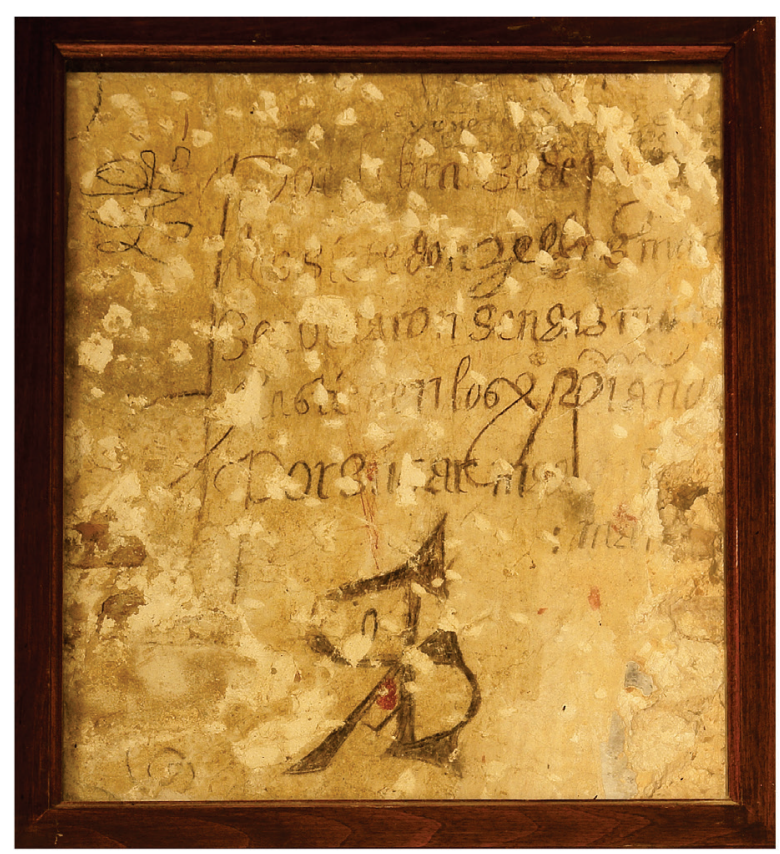

${ }^{9}$ A. DE LA PLAZA BORES: Archivo General de Simancas. Guía del Investigador, Madrid: Ministerio de Cultura, 1992, p. 15, n. 4. V. también, p. 10, n. 2 y p. 14, n. 1. A. CABEZUDO: Antigüedades de Simancas, transcripción por Teresa Salvador Berrueco, Valladolid: Editora Provincial, 2004.

${ }^{10}$ J. PONCE CÁRDENAS: “Góngora y el conde de Niebla. Las sutiles gestiones del mecenazgo", Criticón, 106, pp. 99-146. 


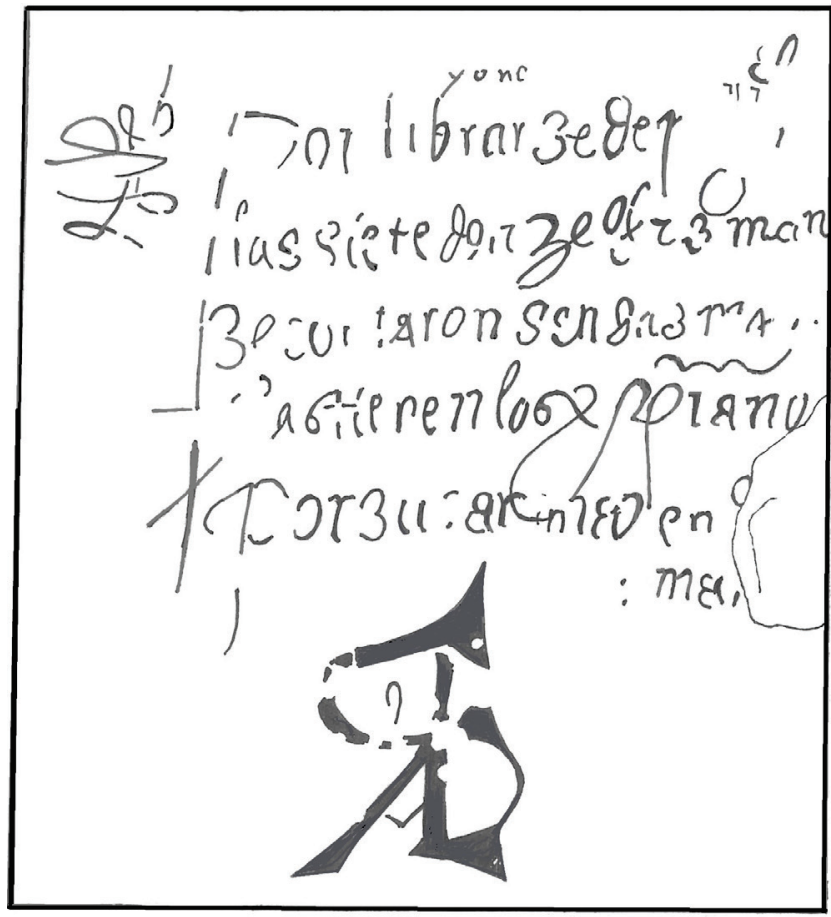

Fig. 4 y 5. Grafito 1 del muro Norte del corredor. Epígrafe de las siete doncellas mancas. Fotografía IAPH. Dibujo de los autores.

\subsection{Grafito 2 del muro Norte del corredor (epígrafe de las firmas)}

Procedente de la misma remodelación de 2005, el grafito 2, llamado tras su aparición "de las firmas", está formado por una serie de trazos, letras, palabras aisladas y pictogramas, pero no por una realidad discursiva. De un espacio original de mayores dimensiones, sólo se ha conservado la superficie enmarcada. Estamos ante un testimonio epigráfico de carácter informal, escrito en color negro sobre una superficie mural, en la que distinguimos posiblemente una rúbrica. En este sentido podemos individualizar la firma "Cabero" y la expresión "penam". También, en la parte superior derecha, aparece un pictograma que puede responder a una marca personal. Está formado por una línea vertical que atraviesa un círculo en su base, que se halla contenido en un triángulo equilátero.

Las dimensiones del campo epigráfico conservado dentro del marco de madera son de 71 por $91 \mathrm{~cm}$. Es difícil asignar una cronología a este grafito. Atendiendo a los datos circunstanciales y al tipo de escritura, humanística bastarda, proponemos como hipótesis el siglo XVIII. 


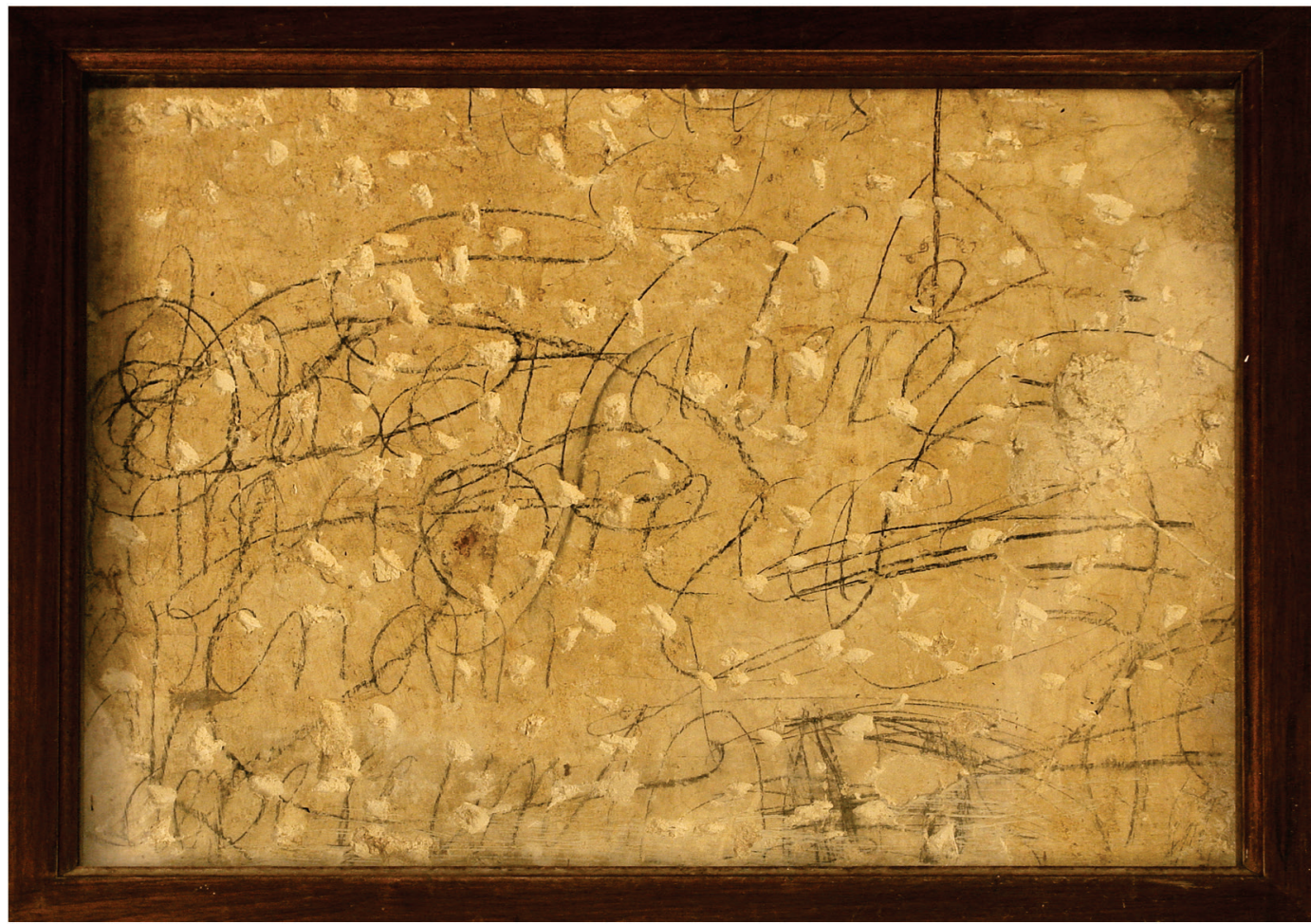

Fig. 6. Grafito 2 del muro Norte del corredor. Epígrafe de las firmas. Fotografía IAPH.

\section{EPÍGRAFE DE LA FUENTE DE LA IGLESIA-CONVENTO DE LA MERCED (1631)}

Esta inscripción se conserva en la "Sala de Arqueología" situada en la sede de la Fundación. Su ubicación original estuvo en la iglesia-convento de la Merced de Sanlúcar. ${ }^{11}$ Esta iglesia fue mandada construir por el octavo duque de Medina Sidonia, que es el personaje que aparece en la inscripción: Manuel Alonso Pérez de Guzmán y Silva. Por lo tanto, la inscripción es contemporánea del epígrafe de las siete doncellas.

Junto con otros elementos patrimoniales de la iglesia de la Merced, la lápida y el escudo fueron trasladados a la sede de la Fundación en los años 60 del siglo XX, por rescate de doña Isabel Álvarez de Toledo, vigesimoprimera duquesa de Medina Sidonia. El motivo del traslado fue evitar el expolio y los destrozos -incluida la cripta con el enterramiento de los duques- que estaba sufriendo el

${ }^{11}$ A. J. MORALES: "Alonso de Vandelvira y Juan de Oviedo en la iglesia de la Merced de Sanlúcar de Barrameda", Boletín del Seminario de Estudios de Arte y Arqueología (BSAA), 47 (1981), pp. 307-320. 
edificio religioso al quedar sin culto. También fueron reubicados otros bienes como mobiliario, objetos litúrgicos y, particularmente, las pinturas de Juan de Roelas, del siglo XVII, así como la talla de la Virgen de la Merced. Todos estos bienes forman hoy parte del patrimonio de la Fundación.

La inscripción es la siguiente:

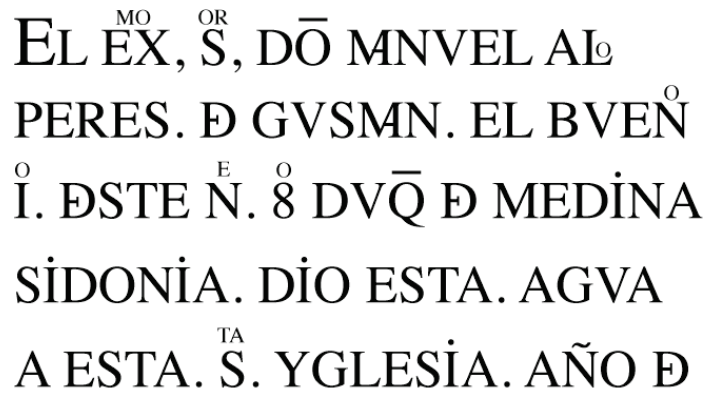

\section{VIVAT. IN ETERNVM}

El excelentísimo señor don Manuel Alonso Peres de Gusmán el Bueno, primero deste nombre, octavo duque de Medina Sidonia, dio esta agua a esta santa yglesia. Año de 1631. Vivat in eternum.

El epígrafe presenta un campo rectangular en forma de una cartela decorada con guirnaldas, espirales y una cabeza alada de ángel en posición central. Sobre el epígrafe aparece el escudo de los Guzmán timbrado con corona ducal y adornado con el collar del toisón de oro. La pieza esta realizada en piedra arenisca. Las dimensiones del escudo son 45 por $30 \mathrm{~cm}$; la inscripción mide 62 por $77 \mathrm{~cm}$; el campo epigráfico propiamente dicho 41 por $61 \mathrm{~cm}$. El grosor de la pieza oscila entre 5 y $7,5 \mathrm{~cm}$.

El texto se dispone en seis líneas de escritura, que ocupan todo el campo epigráfico. El tamaño de las letras es de $4 \mathrm{~cm}$ de alto, salvo la inicial $(5 \mathrm{~cm})$. El espacio interlineal es de $2 \mathrm{~cm}$. El ductus es regular, aunque no se aprecia rastro de pautado. La escritura es humanística mayúscula. El grabado de las letras es triangular. Las interpunciones son comas y puntos con forma de cruz. Hay abreviaturas, habitualmente por letras sobrepuestas $\left(\mathrm{EX}^{\mathrm{MO}}, \mathrm{S}^{\mathrm{OR}}, \mathrm{N}^{\mathrm{O}}, \mathrm{I}^{\mathrm{O}}, \mathrm{N} .{ }^{\mathrm{E}}, 8^{\mathrm{O}}, \mathrm{S}^{\mathrm{TA}}\right)$, aunque también aparece el signo general de abreviación $(\overline{\mathrm{O}}, \overline{\mathrm{Q}})$. También encontramos un nexo (DESTE) y letras enlazadas (MA, DE) e inscritas $\left(\mathrm{L}^{\mathrm{O}}\right)$.

La inscripción es del tipo conocido como Monumentum dotationis. Presenta una composición sencilla, compuesta por cuatro cláusulas: intitulación, notificación, data y fórmula de aprecio. 
La intitulación presenta nombre y apellido del autor (Alonso Pérez de Guzmán el Bueno), precedido de la formula de tratamiento de respeto (excelentísimo señor don), seguido del orden de su nombre en el linaje (primero de este nombre) y del título nobiliario (octavo duque de Medina Sidonia). El verbo notificativo es "dar", seguido de la dación ("dio esta agua") y el beneficiario ("a esta santa iglesia"), es decir, la iglesia-convento de la Merced. Sigue la data, con solo la expresión del año (1631) y termina el texto con una fórmula de aprecio en latín: Vivat in eternum.

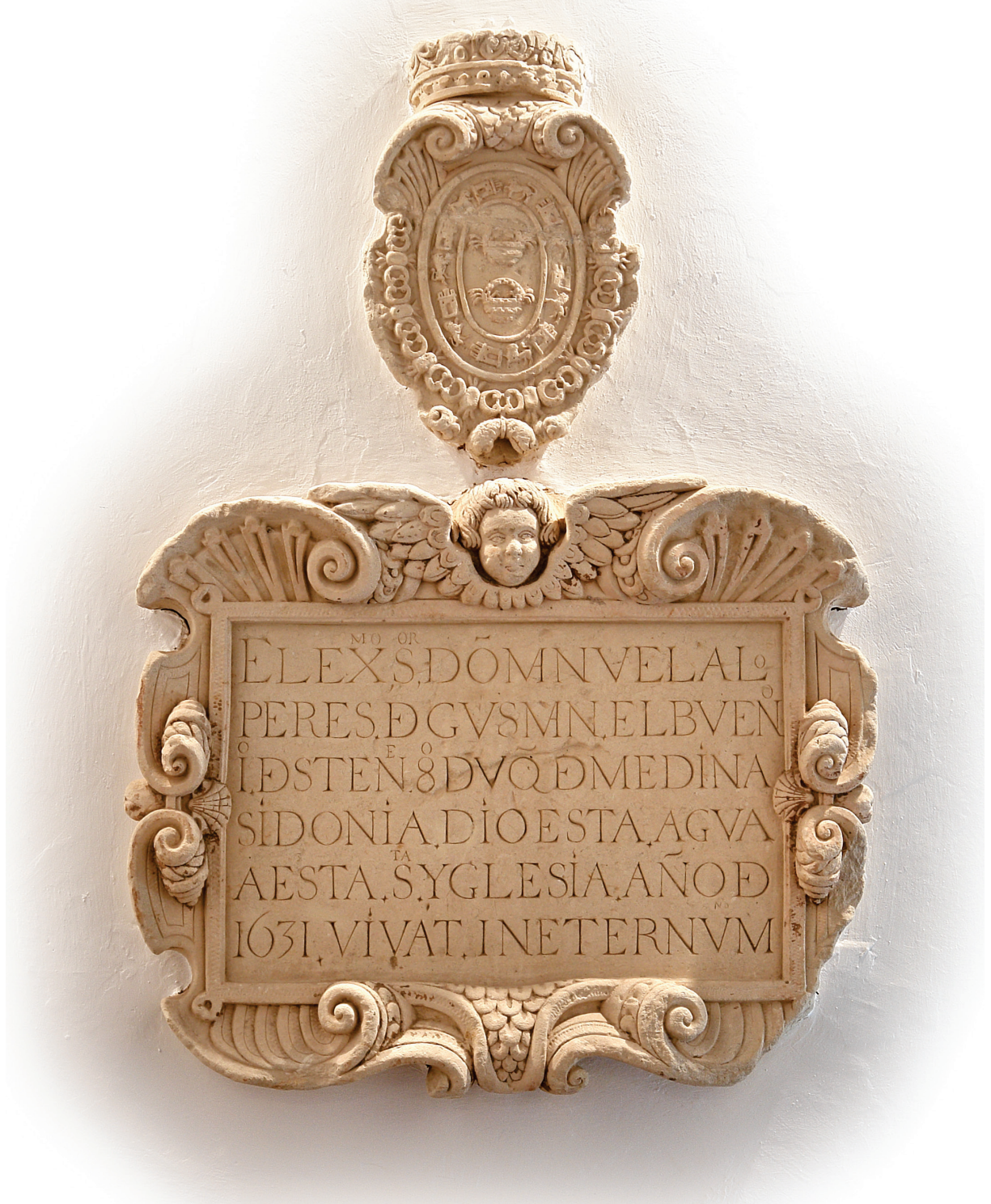

Fig. 7. Epígrafe y escudo de la fuente de la Iglesia-convento de la Merced de Sanlúcar de Barrameda. Fotografía IAPH. 


\section{CONSIDERACIONES FINALES}

Los cuatro epígrafes que hemos presentado son un testimonio de la vitalidad histórica del palacio de los Guzmanes de Sanlúcar de Barrameda, hoy sede de la Fundación Casa de Medina Sidonia. La falta de una excavación sistemática en el subsuelo del palacio nos ha impedido fechar con exactitud así como conocer otros datos importantes sobre la inscripción medieval que apareció en la sala del arco almohade. Pero a la vez nos habla de una riqueza arqueológica que es preciso tener en cuenta para el futuro.

Por su parte, el grafito de las siete doncellas nos informa de la actividad literaria del palacio durante la residencia en él de Alonso Pérez de Guzmán, octavo duque de Medina Sidonia, y de sus relaciones con Valladolid. Un mayor conocimiento de la evolución constructiva del palacio aportará luz sobre este testimonio así como sobre el grafito segundo, que sólo podemos apreciar hoy como un testimonio circunstancial tardío.

Por último, el escudo y el epígrafe de la iglesia-convento de la Merced nos informan del patronazgo y de la actividad constructiva del octavo duque de Medina Sidonia en la localidad sanluqueña. 